Research Article

\title{
Replacing Management or Not: Contract Renegotiation to Prevent Double Moral Hazards of Venture Capital Investments
}

\author{
Linsen Yin $^{1}$ and Ane Pan ${ }^{2}{ }^{2}$ \\ ${ }^{1}$ School of Financial Technology, Shanghai Lixin University of Accounting and Finance, Shanghai 201209, China \\ ${ }^{2}$ School of Management, Wuhan University of Technology, Wuhan 430070, China \\ Correspondence should be addressed to Ane Pan; panane@whut.edu.cn
}

Received 29 March 2021; Revised 15 April 2021; Accepted 19 April 2021; Published 5 May 2021

Academic Editor: Tingsong Wang

Copyright (c) 2021 Linsen Yin and Ane Pan. This is an open access article distributed under the Creative Commons Attribution License, which permits unrestricted use, distribution, and reproduction in any medium, provided the original work is properly cited.

\begin{abstract}
During the venture capital development, replacing the management work team or keeping up the status quo is a key strategy choice for venture capitalist and venture entrepreneur about the long-term development of enterprise and the control right transferring. In fact, the contract designing focuses on the distribution of cash flow to encourage both efforts in order to avoid double moral hazard, and the strategy behavior has similar effects according to the developing condition of venture enterprise. In this paper, we consider both contract design and strategic behavior, regarding this strategic behavior choice as a motivator and combining strategic behavior with financial instrument options. The main innovation is to redesign and optimize the contract based on dynamic perspective, which will analyze initial contract designed to motivate both sides' effort if a venture enterprise is in good state, and then renegotiate whether to replace the management work team or keep up the status quo according to the venture enterprise's development state in the process of venture investment cooperation. The paper also puts forward some conclusions: joint effort of both sides can be motivated through strategic behavior choice and then lead to increasing the overall value of the venture enterprise; after the venture enterprise has gained private benefits in the early stage, the venture capitalist needs to make appropriate assignments and demisability in benefits to remotivate the venture enterprise's efforts, aiming to further balance venture enterprise's private benefits and the earnings redistributed by venture capitalist.
\end{abstract}

\section{Introduction}

Funding difficulties of startup firms can be mitigated by venture capitalists' initial or multiple stage investments, after which the value of venture capital backed firm is shared by venture capitalists and entrepreneurs. However, due to information asymmetry, venture entrepreneurs or management team may take advantage of the actual control right to maximize personal benefits instead of firm value. One typical case is that even entrepreneurs are not well qualified; entrepreneurs tend to continue to operate the firm for private benefits, rather than to be replaced by professional managers, thus causing entrepreneurs' moral hazard that holds up venture capitalists [1-5]. Therefore, it presents a key challenge to venture capitalists to motivate entrepreneurs to maximize the value of the firm and thus the benefits shared by both entrepreneurs and capitalists [6].

Contract instruments selection and arrangements are important means to solve the problem of double moral hazard in the field of venture capital. Previous studies developed models to use financial instruments such as common stock and convertible bonds to motivate both efforts and to prevent double moral hazard [7]. The focus of these studies is to choose and compare different financial tools to motivate the efforts of both sides.

However, contract is not complete as future situation of enterprises cannot be completely predicted. After the venture capitalist and entrepreneur sign an initial contract, they usually will take further actions after they observe situation of the enterprise in its development process. One typical example is that the capitalist who has controlling rights can 
select to keep up the status quo if he observes a good development state of the enterprise or to replace entrepreneur management team by professional managers if he observes a bad development state of the enterprise. Therefore, the enterprise's natural state (as an important uncertain factor) not only affects the efforts level of both sides but also affects or even determines the further strategic choices of both sides, such as whether to maintain the entrepreneur management team and to continue cooperation between both sides.

In this paper, we propose a potential solution for capitalists, that is, an optional choice on replacing managers or keeping up the status quo in initial contract design. This design of renegotiation contract provides capitalists an optional choice to remotivate entrepreneurs after the company has developed to a certain stage and entrepreneurs have attained personal benefits. The remotivation leads entrepreneurs to operate the firm targeted with long-term performance and to keep align their interest with capitalists, thus ensuring the interests of venture capitalists.

Extending the model of Casamatta [2], we redesign and optimize the contract in a dynamic setting. More specifically, we analyze initial contract designed to motivate both sides' efforts from entrepreneurs and capitalists and then renegotiate whether to replace the management team or keep up the status quo according to the enterprise's development state in the process of cooperation between capitalists and entrepreneurs.

The structure of the remainder of this paper is as follows: Section 2 discusses related literature. Section 3 offers basic model description and model assumption. Section 4 presents the contract model combined strategic behavior choice and the corresponding scheme to mitigate double moral hazard. Section 5 describes "Alibaba" case to demonstrate our model. Section 6 concludes the paper.

\section{Literature Review}

There is a growing body of research on the double moral hazard in venture capital investment [8]. In practice, the efforts made by venture capitalist and entrepreneurs cannot be observed due to the incomplete information [9]. Consequently, venture capitalists and entrepreneurs tend to shirk and optimize their own interest and behavior after their own incentives, which leads to less than the first-best level of effort [10]. It brings about double moral hazard between venture capitalists and entrepreneurs.

Some literature suggests using suitable financial instruments to alleviate moral hazard. Admati and Pfleiderer [7] show that a fixed fraction of equity contract can provide robust optimal incentives as it can allocate efficient control rights to venture capitalists. Berglof [11] considers a framework of convertible debt in incomplete contracts to transfer control rights to the value-maximizing party. Based on the work of Hart and Moore [12], the option of the entrepreneur to repudiate her financial obligations limits the feasible amount of outsider claims. Kaplan and Stromberg [13] find that venture capitalists are usually willing to take preferred stock, which can be more suitable to motivate double efforts. Additionally, some literature argues that, in many corporate venturing deals, investors tend to take a majority of equity stake in the startup [13-15]. Overall, these literature focus on designing financing instruments, such as equity and convertible debt, to alleviate moral hazard.

On the other hand, some literature proposes using other approaches for mitigating moral hazard. Neher [16] put forward stage financing as an instrument to implement the optimal investment path. Aghion et al. [17] and Hart et al. [12] propose the contract arrangement combining with contingent control right. They argue that contingent control right allocation can be used as an effective alternative to cash flow rights arrangement, which can make up for the inadequacy of simple contract arrangement of distributing cash flow to prevent double moral hazard.

However, control rights held by venture capitalists cannot be described by the standard array of securities; it should develop a financial contracting model to investigate the joint allocation of control and cash-flow rights attained through contractual covenants in venture capital deals $[14,15]$. Thus, stage financing and contingent control right can be used as important measures according to the development situation of venture enterprise to prevent double moral hazard.

Another issue is what leads to double moral hazard. For example, Cornelli and Yosha [18] analyze the problem of an entrepreneur manipulating short-term results for the purpose of "window-dressing." Inderst et al. [19] find the forming mechanism and fundamental reason of the moral hazard about venture capitalist and venture entrepreneur, which focus on the private gains grabbed by venture capitalist and venture entrepreneur. Bachmann and Schindele [20] argue that venture capitalists try to have theft for commercial secret or invention of venture enterprise, which may damage the profit of venture enterprise.

Recently, scholars show a growing interest in different exit methods of venture capital, attempting to understand the impact of various exit methods on the gains of venture capital company and venture enterprise. For instance, in an empirical analysis of venture capital exit, Cumming [21] found that financing contract differs a lot in terms of cash flow and control, and it differs even more when it comes to considering types of exit (IPO, acquisition, or liquidation) choosing and investment earnings with risk, which not only depends on the characteristics of the venture enterprise but also depends on the distribution of cash flow and control right. Tian et al. [22] design a novel approach that considers both the bounded rationality of venture capitalists and the uncertain circumstance of venture capital in decisionmaking which is urgent to select the promising enterprise in China.

In a separate research, Thomas [23] found that exit clause "investment relationship between the two sides" encouraged venture capitalists to lock the capital into the venture in initial stage. In later stages until the exit, venture capitalists managed to gain more and more control over exit methods by setting up additional seats on the board and gained exit control right in the contract. As a result, the control right was gradually transferred from venture 
entrepreneurs to venture capitalists with the increase of venture capital. Babich et al. [8] model a bargaining game with a moral-hazard problem between an entrepreneur and a bank and a double-sided moral-hazard problem between the entrepreneur and a VC with respect to their noncontractible efforts. The research decomposes the economic value of crowdfunding into cash gains or losses, costs of bad investments avoided, and project-payoff probability update.

Based on the distribution structure and evolution rules of decision-making right and control right of German venture capital samples, Bienz and Walz [24] found that venture capitalists could gain valuable exit right when they return the operation right to entrepreneurs in the investment and cooperation period. An additional finding is that the shorter the contract term is, the more control right is transferred to the hands of the venture capitalists.

Combining the strategy choice behavior of venture capital, it is important and deserves much research work on the contract designing and optimization under the framework with various strategy choices, which is also a new research angle of view. In present research, the aims are to design contract or compare and choose contract to motivate more effort of venture capitalist and venture entrepreneur and to choose strategy behavior to threaten venture capitalist and venture entrepreneur in order to motivate their effort, but it goes blank to study on the contract designing and optimization under the framework with various strategy choices. Therefore, the paper will focus on making up the deficiency, which will design contract considering various strategy choices.

\section{Model Description and Basic Assumptions}

Based on the model developed by Casamatta and Haritchabalet [25], venture capitalist and entrepreneur sign a contract. In the contract, the capitalist invests money, while the entrepreneur invests expertise in each stage. The investment and expertise from both sides determine the total revenue of the venture enterprise. The incentive arrangement is set by the equity allocation scheme, which forms the income distribution to both sides. In this paper, we consider adding a term in the contract, in which the capitalist has an optional strategic choice; that is, he can maintain the status quo or replace venture entrepreneurs with professional managers according to the state of the enterprise after investment. The strategic choice not only relieves the capitalist the worry on the reducing effort of the entrepreneur but also increases the total income of the enterprise, thus increasing the incentive of the entrepreneur.

Consider a venture entrepreneur (hereafter EN) endowed with an innovative investment project. The EN has the creativity and technical skills, but, due to wealth constraint, he needs a sum of investment fund $I$ from a venture capitalist (hereafter VC). The entrepreneur EN and capitalist VC sign an initial contract, which requires $\mathrm{VC}$ to provide the fund $I$ to cooperate with the entrepreneurial project. The contract also formulates an income distribution arrangement according to which VC and EN share the benefits after the termination of the project and the realization of earnings.
Assume that two sides have made detailed due diligence and investigation on the project and have a common understanding for the future development of the project. Both sides think that the project is worth investing before signing the initial contract. These above are all common knowledge.

Investment process is roughly divided into the five following stages:

Stage 1: sign the initial contract $(I, \phi)$, in which $I$ is the initial capital invested by VC and $q W_{s}+b \geq W_{r} \geq b$ is the income shared by both sides.

Stage 2: both sides exert efforts. $e$ and $a$ are the efforts exerted by EN and VC, respectively.

Stage 3: the state of the enterprise $\theta$ can be observed step by step, but it cannot be confirmed.

Stage 4: according to the state $\theta$ of the enterprise, both sides take the corresponding strategic behavior.

Stage 5: final revenue of the enterprise is realized, and both sides share the benefits according to the initial contract or renegotiation contract.

Project schedule is shown in Figure 1.

3.1. Assumption of State. Assuming that the natural state is discrete with only two states, $\theta=\left\{\theta_{g} ; \theta_{b}\right\}$, which denote that the venture enterprise is in a good condition $\theta_{g}$ or in a bad condition $\theta_{b}$, respectively. The probability is as follows:

$$
\theta= \begin{cases}\theta_{g}, & \text { Prob }=p(e, a), \\ \theta_{b}, & \text { Prob }=1-p(e, a) .\end{cases}
$$

In stage 3 , whether the enterprise is in a good condition or not is influenced by the efforts devoted by both sides. Assume that the efforts devoted by EN are only of two types: exertion or inexertion, denoted as $e=\{0 ; 1\}$. " $e=1$ " indicates making efforts while " $e=0$ " indicates no efforts. Since we focus on how to motivate the efforts of $\mathrm{EN}$ in this paper, we assume that the efforts devoted by $V C$ are a fixed level $a$; $\Omega=\pi^{V C}+\lambda_{1}\left(q W_{s}-W_{r}-\left(C_{E N} / \mu\right)+b\right)+\lambda_{2}\left(W_{r}-b\right)+\lambda_{3}$ $\left(\pi_{s}-W_{s}\right)+\lambda_{4}\left(\pi_{r}-W_{r}\right)$. Assume that the probability in good state is $p(e, a)=u *(e+a)$, where $\lambda_{2}$. Due to $\lambda_{3}$ and $\lambda_{4}$, then suppose a constant $\left(\partial \Omega / \partial W_{s}\right)=0$ is to ensure the probability $\left(\partial \Omega / \partial W_{r}\right)=0$ is not larger than 1 .

3.2. Assumption of Efforts. Assuming that $\mathrm{VC}$ devotes a fixed level effort $\lambda_{3}$ to the enterprise, the cost is $\lambda_{4}$. If the effort EN devoted is $W_{s}$, that is, making no efforts, then its cost is $W_{r}$; otherwise, if the effort EN devoted is $\lambda_{1}=\mu(1+a)>0$, that is, making efforts, then the cost is $\lambda_{2}=1>0$. Therefore, EN can save its opportunity cost $\lambda_{3}=0$ if he makes no effort.

3.3. Assumption of Project Revenue under Different Strategic Behaviors. After observing the natural state $\theta$, VC determines by himself or negotiates with EN to select strategic behaviors. One strategic choice is to maintain the status quo; that is, EN continues with the operation according to the business plan, which is defined as $A_{s}$. The other choice is to employ professional managers to replace $\mathrm{EN}$, which is 


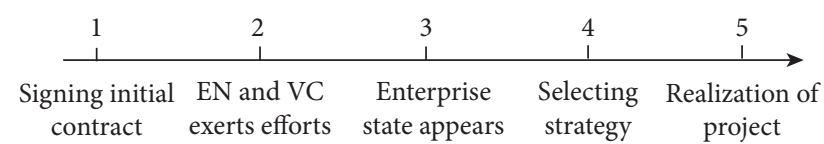

Figure 1: Game event sequence diagram under the contract arrangement.

defined as $A_{r}$. These two different strategic behaviors are denoted as $A=\left\{A_{s} ; A_{r}\right\}$. These two strategic behaviors lead to different project profit and private benefit of EN.

Assume that both VC and EN are risk-neutral. The total revenue of the project is divided into two components: the project revenue shared by VC and EN and the private benefit exclusively owned by EN. It is because EN who is responsible for the daily operation is more familiar with the situation of the project than $\mathrm{VC}$, which leads to the fact that EN can get extra private benefit through his operating over the enterprise.

Consider selecting strategic behavior $A_{s}$, that is, maintaining the status quo. EN can always get the private benefit $b$ if he is not replaced. The project revenue depends on the enterprise's natural state. When the enterprise is in a good condition (natural state $\theta_{g}$ ), it may obtain a high project revenue $\pi_{s}$ with a probability of $q$; or it may obtain a low project revenue 0 with a probability of $1-q$. When the enterprise's natural state is bad $\left(\theta_{b}\right)$, keeping up the status quo will lead to failure of the enterprise project, and the project revenue surely is 0 .

If selecting strategic behavior $A_{r}$, that is, EN is replaced by professional managers, EN has no private benefit, since he lost the operation of the enterprise. The project revenue will not be affected by the enterprise's natural state because the enterprise is operated by professional managers and the effort devoted by VC is still in a fixed level. So, no matter what the natural condition is ( $b$ or $\left.A_{r}\right)$, the project revenue is stable, which is denoted as $b$.

Table 1 summarizes the project revenue of the enterprise and private benefit of EN under different strategic behaviors in two natural conditions.

Chan et al. [3], Hellmann [26], and Gebhardt et al. [27] have provided detailed analyses on how to choose strategic behavior under these two conditions. Their main conclusions are as follows. When the enterprise is in good condition, it should keep the status quo, that is, keep EN continue to operate the enterprise, because the good condition indicates that the enterprise has a good prospect under the operation of EN. However, when the enterprise is in a bad state, EN should be replaced. According to the above conclusion, we make the following assumption on the relationship between the project revenue and private benefit.

$$
\begin{gathered}
q \pi_{s}+b>\pi_{r}>b, \\
q \pi_{s}>\pi_{r} .
\end{gathered}
$$

Formula (2) suggests that an optimal strategic behavior will be determined by maximizing the total revenue of the project, that is, the sum of the project revenue shared by EN and VC and private benefit of EN. In the natural state $\theta_{g}$,
TABle 1: Project revenue under different enterprise's natural state and strategic behavior.

\begin{tabular}{lcccc}
\hline $\begin{array}{l}\text { State } \\
\text { behavior }\end{array}$ & $\begin{array}{c}\text { Project }^{\theta_{g}} \\
\text { revenue }\end{array}$ & $\begin{array}{c}\text { Private } \\
\text { benefit }\end{array}$ & $\begin{array}{c}\text { Project } \\
\text { revenue }\end{array}$ & $\begin{array}{c}\theta_{b} \\
\text { Private } \\
\text { benefit }\end{array}$ \\
\hline$\theta_{b}$ & $A_{r}$ & $\theta_{b}$ & 0 & $b$ \\
$A_{r}$ & $\pi_{r}$ & 0 & $\pi_{r}$ & $\rho$ \\
\hline
\end{tabular}

$A_{r}+b>\pi_{r}$ is to ensure that strategic behavior $A_{s}$ is selected, while $\pi_{r}>b$ is to ensure that strategic behavior $A_{r}$ is selected when in natural state $A_{r}$.

Formula (3) suggests that optimal strategic behavior is to maximize the project revenue shared by $\mathrm{VC}$ and $\mathrm{EN}$, without considering the private benefit of EN. When the enterprise is in good natural state, $A_{r}>\pi_{r}$ is to ensure that strategic behavior $A_{s}$ is selected, while strategic behavior $A_{r}$ is selected because $\pi_{r}>0$.

EN can not only share the monetary revenue of the project but also have private benefit of the enterprise when he operates and controls the enterprise [28]. Thus, EN can gain private benefits if he maintains the status quo. So, even in the natural state $W_{r}$, EN may hope to keep up the status quo $\widehat{W}_{r}$ rather than effective strategic action 0 because of private benefits when the project revenue EN shared is less than the private benefit. This is moral hazard of EN due to pursuing private benefit.

3.4. Description of Social Value Constraints. After exerting fixed level effort $a$, VC needs to encourage EN to take effort $e=1$ to maximize his profit, since EN can choose to make effort $e=1$ or make no effort $e=0$. To ensure that the behavior exerted by $\mathrm{EN} e=1$ is more effective than the behavior $e=0$, we formulate a constraint from the aspect of social value as follows:

$$
\begin{aligned}
& \mu(1+a)\left(q \pi_{s}+b\right)+[1-\mu(1+a)] \pi_{r}-C_{V C}-C_{E N} \\
& \quad>\mu a\left(q \pi_{s}+b\right)+(1-\mu a) \pi_{r}-C_{V C} .
\end{aligned}
$$

Formula (4) shows that the social value when EN takes effort is bigger than that when EN takes no efforts.

\subsection{Description of Revenue Allocation Scheme of the Contract.} The initial contract stipulates the revenue allocation scheme for $\mathrm{VC}$ and EN under different strategic behavior choices. The initial contract $\phi$ is as follows.

Under the strategic action $A_{s}$, the project revenue of the enterprise is $A_{s}$, and the benefit distributed to $\mathrm{EN}$ is $\theta_{b}$, while under the strategic action $\max \Phi=\left(\widehat{W}_{r}-b\right)^{\rho}\left(\pi_{r}-\widehat{W}_{r}\right)^{1-\rho}$, the project revenue is $\widehat{W}_{r} \geq \widehat{W} b$, and the benefit distributed to $E N$ is $\pi_{r} \geq \widehat{W}_{r}$.

VC and EN both have limited liability, so limited liability (LL) constraint should be met:

$$
\begin{aligned}
& 0 \leq W_{s} \leq \pi_{s}, \\
& 0 \leq W_{r} \leq \pi_{r} .
\end{aligned}
$$




\section{Contract Designing with Strategy Behavior Choices}

4.1. Initial Contract Designing Based on the Double Moral Hazard. The purpose of designing an initial contract between VC and EN is to improve efforts of both sides based on maximizing their own benefits. In a well-designed initial contract, optimal strategic action $A_{s}$ is taken by both VC and EN when the enterprise is in a natural state $\theta_{g}$, while $A_{r}$ is selected when the enterprise is in the state $\theta_{b}$.

4.1.1. Constraints Designed to Motivate EN. To maximize his revenue, EN takes strategic action $A_{s}$ when the natural state of the enterprise is $\theta_{g}$, while EN takes strategic action $A_{r}$ when in a natural state $\theta_{b}$. Thus, the following condition $(\mathrm{C}$ 1) should be satisfied:

$$
(\mathrm{C}-1): q W_{s}+b \geq W_{r} \geq b .
$$

On the other hand, to motivate EN to make efforts $e=1$ instead of $e=0$, the following incentive compatibility (IC) constraints should be satisfied simultaneously in the initial contract allocation scheme:

$$
\begin{aligned}
& \text { (IC): } \mu(1+a)\left(q W_{s}+b\right)+[1-\mu(1+a)] W_{r}-C_{E N} \\
& \quad \geq \mu a\left(q W_{s}+b\right)+(1-\mu a) W_{r} .
\end{aligned}
$$

Formula (7) is simplified as follows:

$$
q W_{s}-W_{r} \geq \frac{C_{E N}}{\mu}-b .
$$

4.1.2. Optimization of Contract to Motivate VC. When VC and EN negotiate the initial contract allocation scheme, VC maximizes his own benefit through the arrangement of payoff $W_{s}$ and $W_{r}$, while ensuring that EN make efforts $e=1$ instead of $e=0$.

Therefore, contract optimization problem of VC can be described as

$$
\begin{aligned}
\max _{W_{s}, W_{r}} \pi^{\mathrm{VC}}= & \mu(1+a) q\left(\pi_{s}-W_{s}\right)+[1-\mu(1+a)]\left(\pi_{r}-W_{r}\right) \\
& -C_{\mathrm{VC}}, \\
& \text { S.T. (IC): } q\left(W_{s}-W_{r}\right) \frac{C_{E N}}{\mu}-b, \quad W_{r} \geq b, \\
& (\mathrm{LL}): W_{s}-\pi_{s}, \quad W_{r}-\pi_{r} .
\end{aligned}
$$

This is a nonlinear programming problem satisfying the Kuhn-Tucker conditions, which can be solved by using the Kuhn-Tucker theorem. Assume that

$$
\begin{aligned}
\Omega= & \pi^{\mathrm{VC}}+\lambda_{1}\left(q W_{s}-W_{r}-\frac{C_{\mathrm{EN}}}{\mu}+b\right)+\lambda_{2}\left(W_{r}-b\right) \\
& +\lambda_{3}\left(\pi_{s}-W_{s}\right)+\lambda_{4}\left(\pi_{r}-W_{r}\right),
\end{aligned}
$$

where $\lambda_{1}, \lambda_{2}, \lambda_{3}$, and $\lambda_{4}$ are the Lagrange multipliers of each constraint (IC and LL).

Let $\left(\partial \Omega / \partial W_{s}\right)=0$, and $\left(\partial \Omega / \partial W_{r}\right)=0$, so we can get the Kuhn-Tucker conditions:

$$
\left\{\begin{array}{l}
-\mu(1+a) q+\lambda_{1} q-\lambda_{3}=0 \\
-[1-\mu(1+a)]-\lambda_{1}+\lambda_{2}-\lambda_{4}=0 \\
\lambda_{1}\left(q W_{s}-W_{r}-\frac{C_{E N}}{\mu}+b\right)=0 \\
\lambda_{2}\left(W_{r}-b\right)=0 \\
\lambda_{3}\left(\pi_{s}-W_{s}\right)=0 \\
\lambda_{4}\left(\pi_{r}-W_{r}\right)=0 .
\end{array}\right.
$$

By analyzing whether $\lambda_{1}, \lambda_{2}, \lambda_{3}$, or $\lambda_{4}$ is zero, we can find $W_{s}$ and $W_{r}$ which meet the inequality above. The results where the values of $\lambda_{1}, \lambda_{2}, \lambda_{3}$, and $\lambda_{4}$ satisfy the Kuhn-Tucker conditions are

$$
\begin{aligned}
& \lambda_{1}=\mu(1+a)>0, \\
& \lambda_{2}=1>0, \\
& \lambda_{3}=0, \\
& \lambda_{4}=0 .
\end{aligned}
$$

Thus, the revenue that is allocated to $\mathrm{EN}$ is

$$
\begin{aligned}
& W_{s}=\frac{C_{\mathrm{EN}}}{\mu q}, \\
& W_{r}=b .
\end{aligned}
$$

Formula (13) suggests that, under condition (C-1) in formula (6), $q W_{s}+b \geq W_{r} \geq b$, VC and $E N$ only stipulate in the initial contract where the income allocated to $E N$ is $W_{s}=$ $\left(C_{E N} / \mu q\right)$ when keeping $E N$ to operate the enterprise, while the income allocated to $E N$ becomes $W_{r}=b$ when replacing $E N$ with professional managers. This allocation scheme ensures that EN takes the effective strategic action actively and makes efforts without renegotiating or redesigning the income allocation scheme. At the same time, it will also relieve VC the "hold up" of moral hazard caused by EN selecting alternative ineffective strategic choice through his control of core resources of the enterprise. 


\subsection{Renegotiation of Contract}

4.2.1. The Condition of the Renegotiation of Contract. As noted above, EN may attain large private benefit at the cost of the enterprise's long-term interests. When the private benefit is big beyond a certain threshold, it is necessary for $\mathrm{VC}$ to readjust the initial contract.

Consider the condition of readjusting the initial contract: $b>W_{r}$. When the enterprise is in the natural state $\theta_{b}$, EN takes the strategic action $A_{s}$ and maintains the operation of the enterprise. Although the project revenue is zero and $E N$ gets zero revenue, EN can attain private benefit $b$. If the strategic action $A_{r}$ is taken to replace EN by professional managers, EN loses his private benefit $b$ because of the replacement; thus EN can only get the allocation revenue $W_{r}$ according to the initial contract. Obviously, if $b>W_{r}$, it is better for EN to stay in the enterprise instead of being replaced by professional managers.

Therefore, if the revenue allocated to $\mathrm{EN} W_{r}$ is less than the private benefit $b$ in the initial contract, EN will try to stay in the enterprise instead of actively hiring professional managers even when the enterprise is in a bad state. Although this action is at the cost of the interest of VC, it is optimal for EN. This is the moral hazard caused by the nominal control of the entrepreneur, which is also called the moral hazard that entrepreneurs "hold up" venture capitalists in some literature.

4.2.2. Optimization of Renegotiation Contract. To eliminate the moral hazard that holds up VC, an effective solution is $\mathrm{VC}$ and EN renegotiates to redesign the initial allocation contract after observing the natural state $\theta_{b}$. By increasing the entrepreneur's distributed revenue during reallocating the revenue of the enterprise, EN will actively take the effective strategic action $A_{r}$ when in the natural state $\theta_{b}$; thus, the moral hazard of EN is eliminated.

The key term in the renegotiation contract is to optimize $\widehat{W}_{r}$ to realize the Pareto improvement of the benefit of both $\mathrm{EN}$ and VC. Let us denote $\widehat{W}_{r}$ as the revenue of the enterprise in the renegotiation contract to motivate EN actively to take the strategic action $A_{r}$, that is, actively hiring professional managers to replace himself. Table 2 describes the
TABLE 2: Revenue distributed to EN and VC in the natural state $\theta_{b}$.

\begin{tabular}{cccc}
\hline & \multicolumn{2}{c}{ In the initial contract } & $\begin{array}{c}\text { In the renegotiation } \\
\text { contract }\end{array}$ \\
& $\begin{array}{c}\text { Revenue under } \\
A_{s}\end{array}$ & $\begin{array}{c}\text { Revenue under } \\
A_{r}\end{array}$ & Revenue under $A_{r}$ \\
\hline $\mathrm{EN}$ & $b$ & $W_{r}$ & $\widehat{W}_{r}$ \\
$\mathrm{VC}$ & 0 & $\pi_{r}-W_{r}$ & $\pi_{r}-\widehat{W}_{r}$ \\
\hline
\end{tabular}

distribution of enterprise's revenue under the new allocation scheme when the enterprise is in a bad natural state $\theta_{b}$.

During the negotiation process, the reallocation of the revenue depends on bargain power between $\mathrm{VC}$ and $\mathrm{EN}$. We denote fine $\rho$ as the bargaining power of $E N$, and $1-\rho$ is the bargaining power of VC. Based on Nash equilibrium of bargaining game, we construct the following optimizing problem realizing the Pareto improvement:

$$
\begin{aligned}
\max _{\widehat{W}_{r}} \Phi & =\left(\widehat{W}_{r}-b\right)^{\rho}\left(\pi_{r}-\widehat{W}_{r}\right)^{1-\rho}, \\
\text { S.T. } \quad \widehat{W}_{r} & \geq b, \pi_{r} \geq \widehat{W}_{r} . \\
\text { Let }\left(\partial \Phi / \partial \widehat{W}_{r}\right) & =0 \text {, so we get } \\
(1-\rho)\left(\widehat{W}_{r}-b\right) & =\rho\left(\pi_{r}-\widehat{W}_{r}\right), \\
\widehat{W}_{r} & =(1-\rho) b+\rho \pi_{r}=b+\rho\left(\pi_{r}-b\right) .
\end{aligned}
$$

Besides ensuring that EN actively hires professional managers to eliminate the moral hazard of "hold up" in the natural state $\theta_{b}, \mathrm{VC}$ also needs to motivate EN to make efforts instead of making no efforts in the renegotiation contract. Incentives' compatibility condition is

$$
\begin{gathered}
(\mathrm{IC}): \mu(1+a)\left(q W_{s}+b\right)+[1-\mu(1+a)]\left[(1-\rho) b+\rho \pi_{r}\right] \\
-C_{E N} \geq \mu a\left(q W_{s}+b\right)+(1-\mu a)\left[(1-\rho) b+\rho \pi_{r}\right] .
\end{gathered}
$$

The above formula can be simplified as

$$
q W_{s} \geq \frac{C_{\mathrm{EN}}}{\mu}+\rho\left(\pi_{r}-b\right) .
$$

Therefore, the optimization problem of VC can be described as

$$
\begin{aligned}
& \max _{W_{s}} \pi^{\mathrm{VC}}=\mu(1+a) q\left(\pi_{s}-W_{s}\right)+[1-\mu(1+a)]\left(\pi_{r}-\widehat{W}_{r}\right)-C_{\mathrm{VC}}, \\
& \text { S.T. (IC) } q W_{s} \geq \frac{C_{\mathrm{EN}}}{\mu}+\rho\left(\pi_{r}-b\right),(1-\rho)\left(\widehat{W}_{r}-b\right)=\rho\left(\pi_{r}-\widehat{W}_{r}\right),
\end{aligned}
$$

This is an extreme value problem satisfying Kuhn-Tucker conditions. Similarly, we can get the solution of revenue reallocation in the renegotiation contract as follows:

$$
(\mathrm{LL}): W_{s} \leq \pi_{s}, W_{r} \leq \pi_{r}
$$

$$
\begin{aligned}
& W_{s}=\frac{C_{\mathrm{EN}}}{\mu q}+\frac{\rho\left(\pi_{r}-b\right)}{q}, \\
& \widehat{W}_{r}=b+\rho\left(\pi_{r}-b\right) .
\end{aligned}
$$


4.2.3. Discussion on the Bargaining Power $\rho$. Calculating the first derivative of $W_{s}$ and $\widehat{W}_{r}$ in formula (19) with respect to $\rho$, we can get

$$
\begin{aligned}
& \frac{\partial W_{s}}{\partial \rho}=\frac{\pi_{r}-b}{q}>0 \\
& \frac{\partial \widehat{W}_{r}}{\partial \rho}=\pi_{r}-b>0 .
\end{aligned}
$$

Obviously, we have

$$
\frac{\partial W_{s}}{\partial \rho}>\frac{\partial \widehat{W}_{r}}{\partial \rho}>0 .
$$

From formula (20), we find that the stronger the bargaining power of $\mathrm{EN}$ is, the higher the revenue EN required. That is, whether the enterprise is in the good state or in the bad state, the revenue distributed to $E N\left(W_{s}\right.$ or $\left.\widehat{W}_{r}\right)$ and his bargaining power $\rho$ are positively correlated. On the other hand, formula (21) shows that the margin increasing rate of $W_{s}$ to $\rho$ is higher than that of $\widehat{W}_{r}$ to $\rho$. It suggests that EN's bargaining power can help EN get more compensation when EN stays in the enterprise compared to when he is replaced.

The above conclusion is also reasonable in practice. EN's negotiating power comes from his specialty of human capital. When EN has a high specialty of human capital, this specialty is important and difficult to be replaced for the development of the enterprise. So this specialty of human capital provides EN a high bargaining power in the renegotiation process. Consequently, $V C$ has to distribute more revenue to $\mathrm{EN}$ to maximize his benefit.

4.3. Implications. As discussed in Section 4.2, when the enterprise is in a bad operation state, the revenue shared by $\mathrm{VC}$ and EN decreases; thus the revenue distributed to EN also decreases. So if the private benefit extracted by EN is greater than a threshold, EN will pursue this private benefit but will not be concerned about the revenue shared by $\mathrm{VC}$ and EN. Although this action maximizes EN's benefit, it damages the benefit of VC. This is the reason why VC needs to renegotiate with $\mathrm{EN}$ through distributing more revenue to $\mathrm{EN}$. The implication is that it is necessary for $\mathrm{VC}$ to restrain EN pursuing the private benefit, which not only directly improves the operation efficiency of the enterprise but also motivates EN to take effective action when the enterprise is in a bad state. The measures of restraining EN's pursuit of private benefit include increasing transparency of the enterprise, reducing information asymmetry between EN and $\mathrm{VC}$, and enhancing financial control on the enterprise during the process of providing services and advices to EN.

Secondly, comparing the revenue distributed to EN in the initial contract expressed in formula (13) and that in the negotiation contract expressed in formula (19), we find that the latter is bigger than the former. This suggests that $V C$ needs to distribute more revenue to EN in the negotiation process to remotivate $\mathrm{EN}$ when $\mathrm{EN}$ can get a large private benefit; thus the higher revenue which EN attained in the negotiation process leads EN to select strategic behavior according to the long-term interests of the enterprises instead of private interests.

Thirdly, in the renegotiation contract, the bargaining power of EN plays a key role in the revenue allocation. Strengthening mutual understanding between both sides, enhancing the information transparency, and reducing the information asymmetry help to weaken the bargaining power of EN, thus improving the efficiency of benefit allocation in designing contract.

\section{Case Study}

Owing to commercial secrets and other required secrets, the details of the contract signed by venture capitalist and entrepreneur are not public. It is short of detailed operation and financial situations from the public channels. Thus, researchers usually cannot get enough details to empirically investigate the moral hazard problems from the perspective of contract designing. That is the reason why current literature on the double moral hazard between the capitalist and entrepreneur still stays in the stage of making normative analysis and theoretical design. In this section, we use case study to demonstrate our model. The case is about the cooperation and the corresponding fighting for control rights between Alibaba Group and Yahoo Inc.

5.1. Finding of Venture Enterprise Alibaba Group. Alibaba Group is a China-based group of Internet-based e-commerce businesses including business-to-business online web portals, online retail and payment services, a shopping search engine, and data-centric cloud computing services. The company was founded in the apartment of the current CEO, Jack Ma, in 1999. At that time, Jack Ma and 17 other founders released their first online marketplace named "Alibaba Online"; and, in December 2001, Alibaba Online began to achieve profitability. For seeking broad market space, in May 2003, Taobao was founded as a consumer e-commerce platform; and, in December 2004, Alipay, which started as a service on the Taobao platform, became a separate business. These platforms constitute the key elements of Alibaba Group. In 2012, two of Alibaba's portals together handled 1.1 trillion yuan ( $\$ 170$ billion) in sales, more than the competitors eBay and Amazon.com combined. On 18 September 2014, Alibaba's IPO was priced at US\$68, raising US\$21.8 billion for the company and investors. Alibaba was the biggest U.S. IPO in history. At close time, on the date of its initial public offering (IPO), Alibaba's market value was measured at US\$ 231 billion.

\subsection{Acquiring the Support from Venture Capitalists.} When Jack Ma founded the company, it was just an Internet company, owning a good market idea and computer technology but starving for venture capital. From 1999 to 2000, Alibaba Group raised a total of US\$ 25 million from SoftBank, Goldman Sachs, Fidelity, and some other institutions, which provided initial capital for Alibaba Online startup.

After 6 years of difficult venture, Alibaba Group provided a broad outline for further development. Meanwhile, 
Alibaba Group also met the development bottleneck, starving for a great deal of venture capital and Internet services. Fortunately, Alibaba Group and Yahoo! Inc came together. In October 2005, Alibaba Group formed a strategic partnership with Yahoo! Inc and acquired China Yahoo! (http://www.yahoo.com.cn), a Chinese portal that focuses on Internet services such as news, email, and search. Yahoo became the largest controlling shareholder of Alibaba Group by using $\$ 10$ billion and Yahoo all business in China to change Alibaba Group's 40\% stock rights. Softbank held 29 percent of Alibaba's shares and voting rights.

Thus, Yahoo and Softbank as capitalists of venture enterprise Alibaba Group have formed stable three-side relationship with the entrepreneurs, Jack Ma management team. This stable relationship speeded the development of Alibaba Group. Under the support from the corporation framework of initial contract, Alibaba Group succeeded in making Alipay, Taobao, Taobao mall, Ali cloud, China Yahoo, and so forth into its all wholly owned subsidiaries by the way of acquisition and merge, and Alibaba Group had gotten a rapid development. In 2007, Alibaba.com Ltd. went public on Hong Kong Stock Exchange, which amounted to $15 \$$ billion by Public financing; and in fact the finance amount reached $16.9 \$$ billion if adding the overallotment option at that day, which exceeded the finance amount of $16.7 \$$ billion that Google company went public and get finance and set a new record about finance amount by global Internet company going public. This was a successful investment contract, which promoted the close cooperation between venture capital and venture enterprise and boosted the great success of Alibaba Group.

\subsection{Fighting for Control Rights between Capitalists and} Entrepreneurs. After Alibaba Group got a great success, the war of interest distribution broke out between capitalists and entrepreneurs. In 2009, when Alibaba Group held the tenth anniversary celebration, Yahoo beyond all expectations undersold its hold share of 1\% Alibaba Group's share to improve its sliding in the stock price. Furthermore, Yahoo hoped that Alibaba Group wholly owned subsidiaries, such as Taobao and Alipay, go public, which would bring about high returns and cash flow to Yahoo. This action is to some extent harmful to Alibaba Group as the selling share of its strategic investor released a bad sign to the public.

On the other hand, Alibaba also took a fight back action. As the core of Alibaba Group, Jack Ma and his management team stripped the core business and core subsidiaries, including Alipay and Taobao company from the Alibaba Group, which had not been unauthorized by the shareholder's meeting. This provoked Yahoo that was to use the controlling shareholder's control right to replace Jack Ma and his management team with joint actions of Softbank.

5.4. Renegotiation between Capitalists and Entrepreneurs. Teaming up together again becomes an ideal tendency, when both sides of venture capital and venture enterprise truly understand the idea "Cooperation is a win-win, while fighting leads double defeat."
Yahoo and Alibaba Group have been fighting for themselves about private interests for three years since 2009. They eventually went back to the conference table and renegotiated together. Yahoo began to take some active measures; for example, Yahoo's president stressed that they highly respect Jack Ma's management team and their achievements and promised to devote himself to establishing a good business relationship and continue providing a large amount technical cooperation, including that Yahoo will continue to provide core technology, oversea business, and tunnel and ad-serving platform to help Alibaba Group.

On May 21, 2012, Alibaba announced an agreement with Yahoo. In the agreement, Alibaba would repurchase onehalf of the shares held by Yahoo with $\$ 6.3$ billion in cash and no more than $\$ 800$ million in newly issued Alibaba preferred stock. In September of that year, the repurchase was completed. After the deal, the voting rights of Yahoo and Softbank have declined to less than 50 percent. In the new board of the company, Alibaba, Yahoo, and Softbank would maintain a ratio of $2: 1: 1$. Yahoo also agreed to give up the veto it had wielded over Alibaba's strategic and business decisions. These actions had ensured Jack Ma's management team could have more of a say in such decisions, paving the way for business restructuring and a potential IPO.

5.5. Case Analysis. This case provides a good example for the renegotiation to mitigate double moral hazard between venture capitalists and entrepreneurs.

At the beginning, Alibaba had a good development with the support of Yahoo and Softbank. But after Alibaba had made some initial success, both sides of capitalists and entrepreneurs took some actions based on their own private interests, which were harmful to each other. This is the situation of stage four, which is described in our model. For the long-term development of Alibaba Group, it is necessary for Yahoo, Softbank, and Jack Ma's management team to cooperate closely with each other. Without the help from Yahoo and Softbank, such as Yahoo's technical support and Softbank's good peripheral channels and overseas business, Alibaba would be difficult to make further expansions of their business, especially overseas business. On the other hand, if Yahoo and Softbank replaced Jack Ma's management team using their control right, Alibaba would be a "shell" lacking the soul of Jack Ma as Alibaba had been branded by the values of Jack Ma and his management team.

For the strategic behavior of capitalists, Yahoo and Softbank had two choices. One is to replace Jack Ma's management team with another professional team. The other is to keep up the status quo, that is, letting Jack Ma and his management team control and manage Alibaba Group.

As discussed in our model, how to choose the strategic choice is determined by the state of the enterprise. According to the good development of Alibaba, the capitalist Yahoo should continue to maintain Jack Ma's management team instead of replacing them. But Yahoo needed to find a solution to prevent the management team pursuing private benefit. In this case, Yahoo renegotiated with the 
management team and got a monetary benefit from the exchange between the voting rights and ownership.

From the case, we find that it is normal for the capitalist and entrepreneur try to seek their private benefits. The key is how to choose the strategic behavior to mitigate the double moral hazard. As our model shows, renegotiation of both sides to form a new balance of contract is a good solution, which not only considers mutual interests of both sides but also promotes their efforts. Although this case cannot use empirical data to accurately analyze our contract model, the process of fighting for control rights between Alibaba and Yahoo can still qualitatively describe our idea on mitigating moral hazard by contract designing and optimization under the framework with various strategic behavior choice.

\section{Conclusion}

In this paper, we consider the further strategic choice (renegotiation contract) after signing an initial contract. In the variety process of venture enterprise's development state, whether to keep up the status quo or to replace management team with professional manager is a painful choice for venture enterprise when there appears a certain unfavorable situation. This is a common phenomenon, but this kind of common phenomenon implies that the venture enterprise can take advantage of this opportunity (as a threat). After signing the contract, venture capitalist may threat venture enterprise by ending cooperation in order to motivate venture entrepreneur's effort level. This is a kind of strategy behavior.

Casamatta \& Schmidt's study did not consider using strategic behavior to stimulate the efforts of both sides, while mainly concentrating on the choice of financial instruments. Regarding this strategic behavior choice as a motivator and combining strategic behavior with financial instrument options is an important breakthrough in this paper. Not only is the choice of financial instruments a factor to stimulate efforts of both sides, but also the strategic behavior choice of cooperating or not after contract signing should also be included. This strategic behavior is used as postthreats.

The main breakthrough of this research conclusion is to divide contract into initial contract and renegotiation contract. Initial contract is mainly to motivate effort by the arrangement of financial instruments, while renegotiation contract provides strategic behavior choices of whether to cooperate or replace venture entrepreneur for venture enterprise. On the basis of strategic behavior choices, designing corresponding contract to motivate venture entrepreneur's effort level is an important research frame.

Some conclusions can be reached from renegotiating contract:

(1) Joint effort of both sides can be motivated through strategic behavior choice and then lead to increasing the overall value of venture enterprise. Viewed from the social welfare, it increases social overall benefit and realizes the result of positive-sum game.

(2) After venture enterprise gained private benefits in the early stage, venture capitalist needs to make appropriate assignment and demisability in benefits to remotivate venture enterprise's efforts, aiming to further balance venture enterprise's private benefits and the earnings redistributed by venture capitalist. Once the balance can be greater incentive to venture entrepreneur, he will focus on long-term benefits and give up the private benefits.

(3) There is a close relationship between benefit assignment motivation of venture enterprise's efforts and the bargaining power of venture entrepreneur. Venture capitalist may inhibit the bargaining power of venture entrepreneur appropriately by enhancing information transparency of venture enterprise.

In general, the paper forms a research frame, in which two strategic behavior choices are considered overall to be introduced into contract arrangement, which depends on different conditions to design corresponding contracts optimization, including the non-in-depth analysis of various financial instruments, such as equity contracts and convertible bond contracts. These institutional arrangements have vital significance to motivate both sides' efforts and alleviate double moral hazard.

Follow-up studies can further consider combining strategic behavior choice with contract tools to control or adjust the income distribution between both sides through contingent control, which motivate the efforts of both sides indirectly by combining strategic behavior choice and slow or partly eliminate double moral hazard. This is a more realistic and feasible idea.

\section{Data Availability}

Data sharing is not applicable to this article as no data sets were generated or analyzed during the current study.

\section{Conflicts of Interest}

The authors declare no conflicts of interest.

\section{Acknowledgments}

This work was supported in part by the 2020 Shanghai University Key Undergraduate Education Reform Project "Exploration and Practice of the Construction of New Fintech Majors from the Perspective of the Development of Fintech Industry."

\section{References}

[1] M. J. Barclay and C. G. Holderness, "Private benefits from control of public corporations," Journal of Financial Economics, vol. 25, no. 2, pp. 371-395, 1989.

[2] C. Casamatta, "Financing and advising: optimal financial contracts with venture capitalists," The Journal of Finance, vol. 58, no. 5, pp. 2059-2085, 2010.

[3] Y.-S. Chan, D. Siegel, and A. V. Thakor, "Learning, corporate control and performance requirements in venture capital contracts," International Economic Review, vol. 31, no. 2, pp. 365-381, 1990. 
[4] V. Yerramilli, "Moral hazard, hold-up, and the optimal allocation of control rights," The RAND Journal of Economics, vol. 42, no. 4, pp. 705-728, 2011.

[5] S. Mullainathan and Z. Obermeyer, "Does machine learning automate moral hazard and error?" American Economic Review, vol. 107, no. 5, pp. 476-480, 2017.

[6] F. Thies, A. Huber, C. Bock, A. Benlian, and S. Kraus, "Following the crowd-does crowdfunding affect venture capitalists' selection of entrepreneurial ventures?" Journal of Small Business Management, vol. 57, no. 4, pp. 1378-1398, 2019.

[7] A. R. Admati and P. Pfleiderer, "Robust financial contracting and the role of venture capitalists," The Journal of Finance, vol. 49, no. 2, pp. 371-402, 1994.

[8] V. Babich, S. Marinesi, and G. Tsoukalas, "Does crowdfunding benefit entrepreneurs and venture capital investors?" Manufacturing \& Service Operations Management, vol. 23, no. 2, pp. 508-524, 2021.

[9] A. Cavallo, A. Ghezzi, C. Dell'Era, and E. Pellizzoni, "Fostering digital entrepreneurship from startup to scaleup: the role of venture capital funds and angel groups," Technological Forecasting and Social Change, vol. 145, pp. 24-35, 2019.

[10] H. Fu, J. Yang, and Y. An, "Contracts for venture capital financing with double-sided moral hazard," Small Business Economics, vol. 53, no. 1, pp. 129-144, 2019.

[11] E. Berglof, "A control theory of venture capital finance," Journal of Law Economics \& Organization, vol. 10, no. 2, pp. 247-267, 1994.

[12] O. Hart and J. Moore, "A theory of debt based on the inalienability of human capital," The Quarterly Journal of Economics, vol. 109, no. 4, pp. 841-879, 1994.

[13] S. N. Kaplan and P. Stromberg, "Financial contracting theory meets the real world: an empirical analysis of venture capital contracts," Review of Economic Studies, vol. 70, no. 2, pp. 281-315, 2003.

[14] D. Cumming and S. A. B. Johan, "Advice and monitoring in venture finance," Financial Markets and Portfolio Management, vol. 21, no. 1, pp. 3-43, 2007.

[15] D. J. Cumming and S. A. Johan, Venture Capital and Private Equity Contracting: An International Perspective, Elsevier, Amsterdam, Netherlands, 2013.

[16] D. V. Neher, "Staged financing: an agency perspective," Review of Economic Studies, vol. 66, no. 2, pp. 255-274, 1999.

[17] P. Aghion and P. Bolton, "An incomplete contracts approach to financial contracting," The Review of Economic Studies, vol. 59, no. 3, pp. 473-494, 1992.

[18] F. Cornelli and O. Yosha, "Stage financing and the role of convertible securities," Review of Economic Studies, vol. 70, no. 1, pp. 1-32, 2003.

[19] R. Inderst, H. M. Mueller, and F. Münnich, "Financing a portfolio of projects," Review of Financial Studies, vol. 20, no. 4, pp. 1289-1325, 2007.

[20] R. Bachmann and I. Schindele, Theft and Syndication in Venture Capital Finance, Social Science Electronic Publishing, Rochester, NY, USA, 2006.

[21] D. J. Cumming, "Capital structure in venture finance," Journal of Corporate Finance, vol. 11, no. 3, pp. 550-585, 2005.

[22] X. Tian, Z. Xu, J. Gu, and E. Herrera-Viedma, "How to select a promising enterprise for venture capitalists with prospect theory under intuitionistic fuzzy circumstance?" Applied Soft Computing, vol. 67, pp. 756-763, 2018.

[23] K. P. Thomas, Investment Incentives and the Global Competition for Capital, Palgrave Macmillan UK, London, UK, 2011.
[24] C. Bienz and U. Walz, "Venture capital exit rights," Journal of Economics \& Management Strategy, vol. 19, no. 4, pp. 10711116,2010

[25] C. Casamatta and C. Haritchabalet, Learning and Syndication in Venture Capital Investments, Elsevier, Amsterdam, Netherlands, 2003.

[26] T. Hellmann, "The allocation of control rights in venture capital contracts," The RAND Journal of Economics, vol. 29, no. 1, pp. 57-76, 1998.

[27] G. Gebhardt and K. M. Schmidt, Conditional allocation of control rights in venture capital finance, Ludwig Maximilian University of Munich, Ingolstadt, Germany, 2006.

[28] P. Aghion and J. Tirole, "Formal and real authority in organizations," Journal of Political Economy, vol. 105, no. 1, pp. 1-29, 1997. 